\title{
The Kinematic Model Establishment of Crank \&Linkage with Time under High Rotation in Punching Machine
}

\author{
XU Run", LIU Jiaguang \\ Mechanical Electricity Department, WenJing College, Yantai University, Yantai 264005, China
}

DOI: $10.36348 /$ sjet.2021.v06i04.002 $\quad$ | Received: 09.03.2021 | Accepted: 15.04.2021 | Published: 21.04 .2021

*Corresponding author: XU Run

\section{Abstract}

With increasing time the movement, velocity and acceleration of mold will become sinusoidal wave. When the crank length increases from $40 \mathrm{~mm}$ to $70 \mathrm{~mm}$ under linkage length $\mathrm{L}=160 \mathrm{~mm}$ the maximum movement, velocity and acceleration will increase and the minimum ones will increase. The phase angle will decline with inclining rotation with sinusoidal wave but the size of them maintains unchanged respectively. So it is chosen of the short crank and long linkage so as to maintain maximum force. To be rapid work the rotation is needed highly.

Keywords: Time; rotation; crank length; linkage length; acceleration; punch mold; machine; modeling; kinematics.

Copyright ( ) 2021 The Author(s): This is an open-access article distributed under the terms of the Creative Commons Attribution 4.0 International License (CC BY-NC 4.0) which permits unrestricted use, distribution, and reproduction in any medium for non-commercial use provided the original author and source are credited.

\section{INTRODUCTION}

The velocity and acceleration is to be found the necessary parameters in crank mechanism movement in kinematics of mold. So in a cycle the investigation into kinematic movement is important. Firstly through velocity of mold exhibits the force size directly. It is observed through curve tendency. Secondly the acceleration expresses the force through detail tendency. It is expressed that define value of force change. In order to save material and cost the data on them is essential at all. Such as the detail material choice and manufacture cost is needed reasonably and economically. In this paper the velocity and acceleration is computed through model and it is valuable on their data and tendency. Further research is needed to these parameters behavior to grasp these rule and data. Because the punch machine is applied to many factories the crank is a important mechanism in punch component [1-4]. So the speed of work is most important one to control the production. We shall compute and model the parameter to find an economic mechanism to its application to product designer, operating engineer and machine maker.

Mold can be used in assembly line production, because of its thin thickness; can work in the machine line. In the process of stamping, the coil steel plate and the mold press are connected into four working procedures, and three deep drawing operations in a short time to complete the continuous processing of the motor shell [3-7]. They produce a lot of products in a certain amount of time. Since the production line is an automatic feed mold, it is difficult to control the cost. So we should focus on this cost issue and work for scientific management, networking and digital AI management. Due to excessive machine fatigue and the processing speed is also fast, we need to carry out timely routine inspection of the machinery and equipment and focus on the hidden faults. This saves the cost of the trip to the manufacturer's personnel for repair due to machine failure and the loss caused by the shutdown of the machine. Because the load and frequency of the machine do not keep up with the loss caused by the fatigue condition under the load of the raw material and the die, the economic efficiency of the control structure of the crankshaft is an important factor in the automation industry. This paper discusses the crankshaft from the technical point of view of economic benefit. The crank is the most critical power mechanism, which turns the rotating motion of the spindle into the linear motion of the ramming motor shell and pushes and presses the thin steel plate. Therefore, the kinematics and dynamics of the crank are studied in order to optimize the crank parameters and save energy and high efficiency. 
Kinematic equations

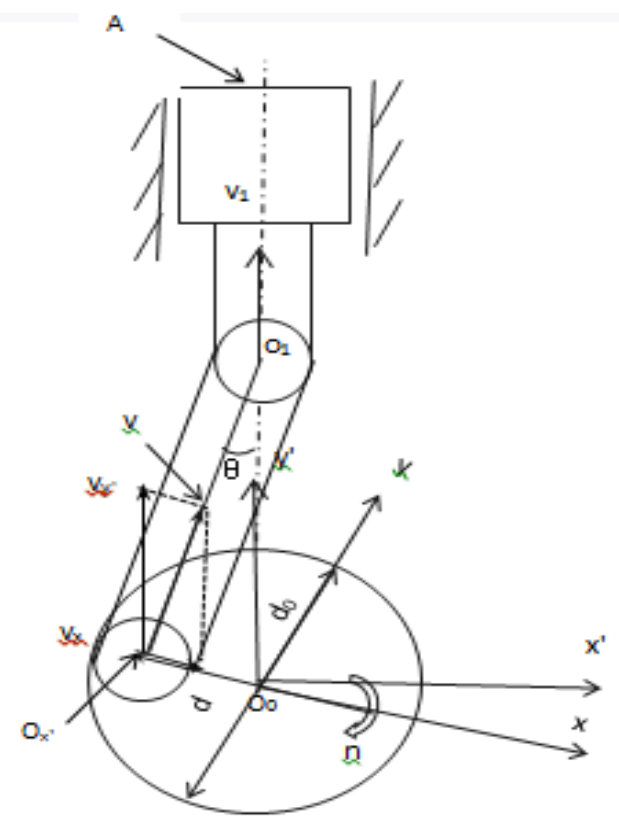

Fig-1: The kinematic of crankshaft linkage length in the first mold process

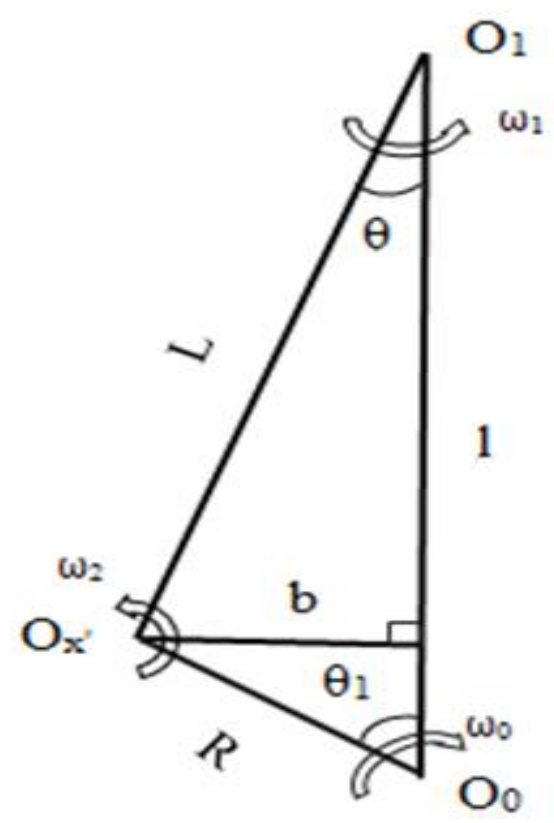

Fig-2: The kinematic of crankshaft linkage length

Figure 1 shows the kinematics diagram of crankshaft connecting rod device. Figure 2 is a schematic diagram of crank linkage mechanism, and the parameter can be derived from the following. $\mathrm{B}$ is perpendicular to the $\mathrm{L}$ and $\mathrm{O}_{1} \mathrm{O}_{0}=\mathrm{L}$.

$$
\begin{aligned}
& l=R \cos \theta_{1}+L \cos \theta \\
& \& b=L \sin \theta=R \sin \theta_{1^{-}}
\end{aligned}
$$

Since law of cosines

$l^{2}=R^{2}+L^{2}-2 R L \cos \theta$
From above (1) (3) it has

$l=\sqrt{L^{2}+R^{2}-2 L R \cos \left[\pi-\arcsin \left(\frac{R}{L} \sin \theta_{1}\right)-\theta_{1}\right]}$

It is formula for mod linkage length movement. As below the velocity and acceleration of mold.

$$
\begin{aligned}
& v_{1}=\frac{d \Delta l}{d t} \\
& a=\frac{d v_{1}}{d t}
\end{aligned}
$$

Here, $\mathrm{n}$ is rotation in shaft, $\mathrm{r} / \mathrm{min}$; $\mathrm{L}$ is the linkage length; $\mathrm{R}$ is crank length; $\mathrm{d}$ is the shaft diameter; $a$ is acceleration of mold; $\theta$ is angle of linkage and center line; $\theta_{1}$ is angle of crank and center line; $t$ is the time; $\Delta \mathrm{L}$ is the relative mold movement [2].

\section{DISCUSSIONS}

It is investigated that what the velocity changes when crank length $\mathrm{R}$ inclines from $40 \mathrm{~mm}$ to $70 \mathrm{~mm}$ in mold of machine meanwhile what the velocity changes when the rotation becomes from $60 \mathrm{r} / \mathrm{m}, 70 \mathrm{r} / \mathrm{m}$ to $80 \mathrm{r} / \mathrm{m} \&$ even $90 \mathrm{r} / \mathrm{m}$ during one cycle course time is detailed explanation in this study. The size of crank length is chosen reasonably for optimum mold length. It is investigated which $\mathrm{R}=40 \mathrm{~mm}, 55 \mathrm{~mm}$ and $70 \mathrm{~mm}$ under $\mathrm{L}=160 \mathrm{~mm}$ is the best one since its energy saving is attained not only, but also the fit mold work size with $8 \mathrm{~cm}, 9.5 \mathrm{~cm}$ and $14 \mathrm{~cm}$ which is the lowest to compare with others in this study. The longest size is for $\mathrm{R}=70 \mathrm{~mm}$ and $\mathrm{L}=160 \mathrm{~mm}$ which has the $14 \mathrm{~cm}$ one for the deepest molding.

It shows the maximum force with different linkage length $\mathrm{L}=160 \mathrm{~mm}$. The periodic distribution of maximum three parameters is from $1 \mathrm{~s} \& 0.85 \mathrm{~s}$ to $0.75 \mathrm{~s}$ $\& 0.67 \mathrm{~s}$ for rotation with $60 \mathrm{r} / \mathrm{m}, 70 \mathrm{r} / \mathrm{m}$ and $80 \mathrm{r} / \mathrm{m} \&$ $90 \mathrm{r} / \mathrm{m}$. The high efficiency is high one with long linkage length and high rotation which causes high force and rapid work to apply to. Deep working with high force and deep movement is adopted big linkage length. It may be deduced from the formula which can incline the acceleration with long linkage so the force will be inclined correspondingly.

Figure 3(a, b) shows that movement of mold becomes sinusoidal wave when the time changes. Meanwhile the one does when the crank and linkage length changes. It will be sinusoidal from positive position to zero one then from zero to negative one finally becomes zero and positive one with a circle. When crank length is $70 \mathrm{~mm}$ and linkage length is $160 \mathrm{~mm}$ the highest movement is formed, then crank length is $55 \mathrm{~mm}$ and linkage length is $140 \mathrm{~mm}$ and the lowest movement is crank length is $40 \mathrm{~mm}$ and linkage 
one is $120 \mathrm{~mm}$. Here the role of crank length is a little and main is linkage length. Figure 3(c, d) shows the similar phenomenon with above Figure $3(\mathrm{a}, \mathrm{b})$ mentioned. In total when rotation is increased the movement will incline a little and the phase angle will decline.

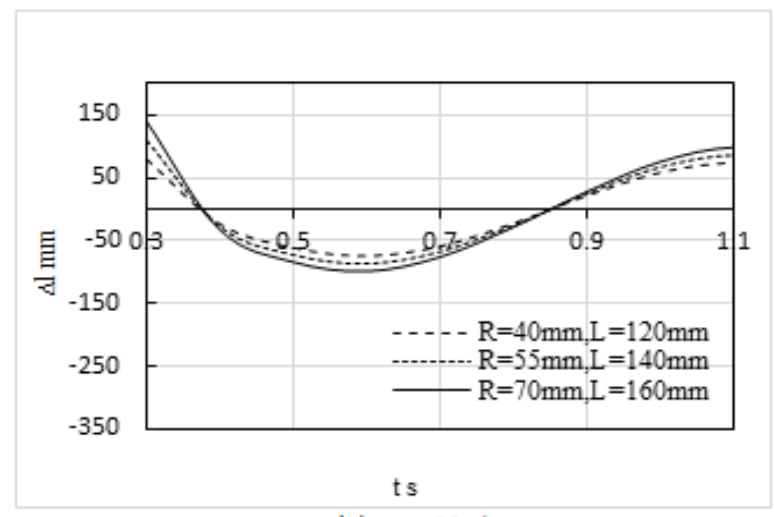

(a) $\mathrm{n}=60 \mathrm{r} / \mathrm{m}$

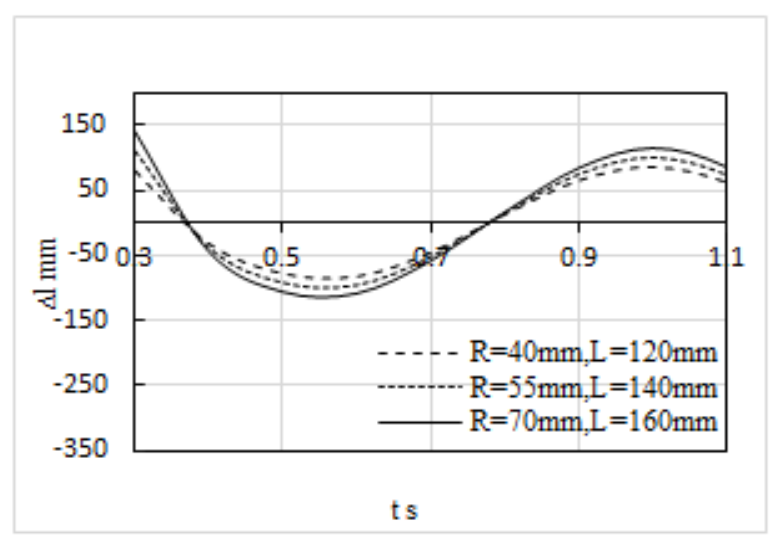

(a) $\mathrm{n}=70 \mathrm{r} / \mathrm{m}$

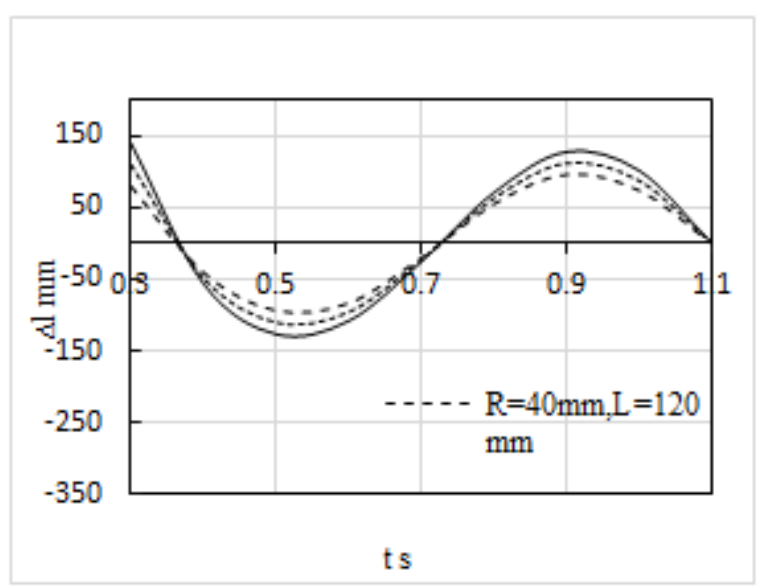

(a) $\mathrm{n}=80 \mathrm{r} / \mathrm{m}$

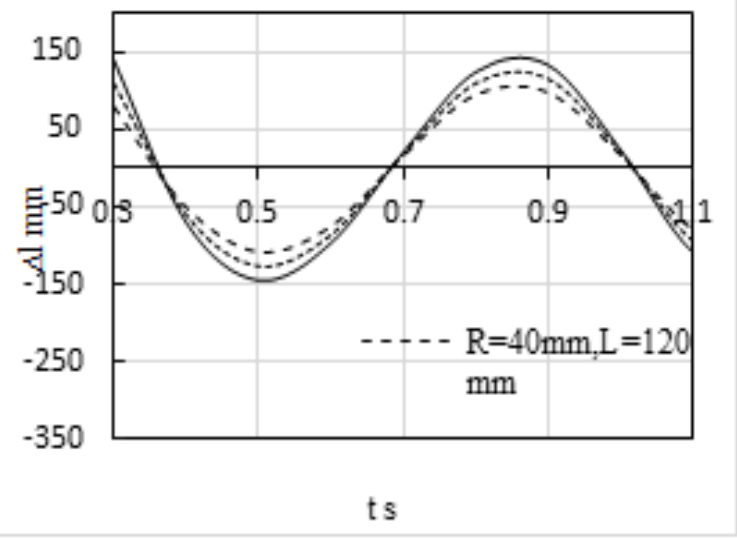

(a) $\mathrm{n}=90 \mathrm{r} / \mathrm{m}$

Fig-3: Relations of strokes movement and time with the parameter $\mathbf{R} \& \mathbf{L}$ under different rotation

Figure 4(a, b) shows that with increasing $R$ from $40 \mathrm{~mm}$ to $55 \mathrm{~mm}$ the valley velocity becomes small. Meanwhile with increasing time it becomes sinusoidal wave, and with increasing linkage length it will incline from $1.2 \mathrm{~m} / \mathrm{s}$ to $-1.2 \mathrm{~m} / \mathrm{s}$ when the time is $0.3 \mathrm{~s}$. Figure $4(\mathrm{a}, \mathrm{b})$ shows that the velocity will be big with rotation $70 \mathrm{r} / \mathrm{m}$. The similar status will be shown with Figure 4(a, b). Figure 4(c, d) shows the velocity will become big with rotation from $80 \mathrm{r} / \mathrm{m}$ to $90 \mathrm{r} / \mathrm{m}$ too. The velocity will arrive to $1.4 \mathrm{~m} / \mathrm{s}$ with time of $0.22 \mathrm{~s}$ with increasing rotation changing from $80 \mathrm{r} / \mathrm{m}$ to $90 \mathrm{r} / \mathrm{m}$, meanwhile it arrives $1.4 \mathrm{~m} / \mathrm{s}$ a little high than $1.2 \mathrm{~m} / \mathrm{s}$ with linkage length of $160 \mathrm{~mm}$. The phase angle of velocity decrease repeatedly when the time attains periodic second with the increasing rotation in this study in general.

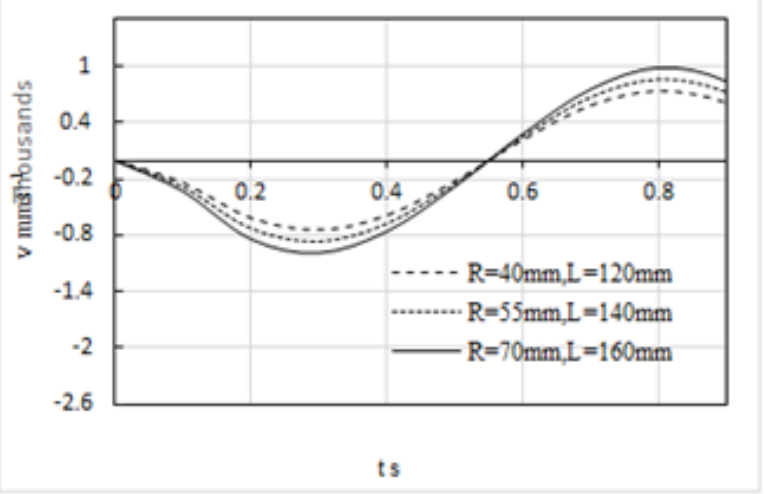

(a) $\mathrm{n}=60 \mathrm{r} / \mathrm{m}$ 
XU Run \& LIU Jiaguang, Saudi J Eng Technol, Apr, 2021; 6(4): 57-61

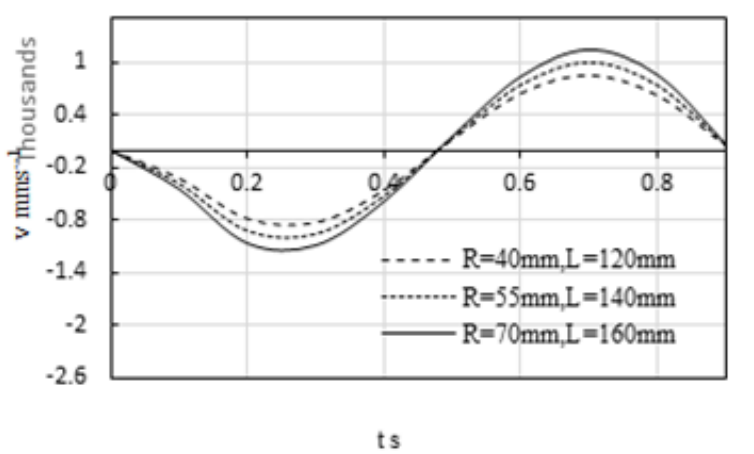

(b) $\mathrm{n}=70 \mathrm{r} / \mathrm{m}$

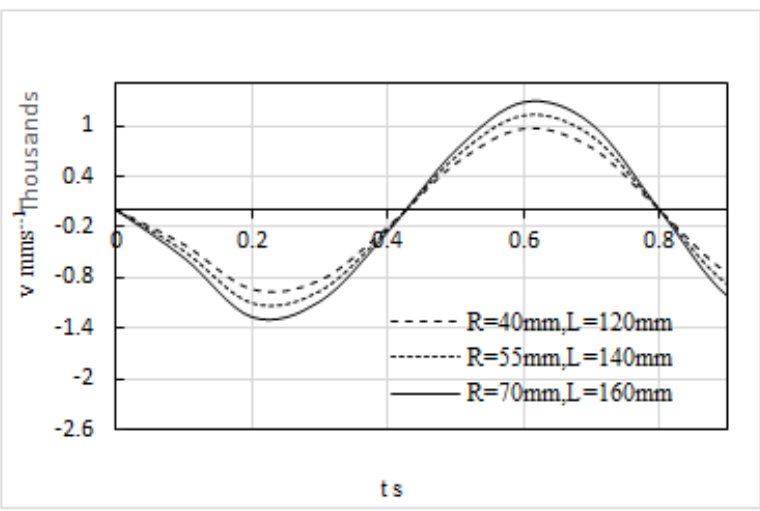

(c) $\mathrm{n}=80 \mathrm{r} / \mathrm{m}$

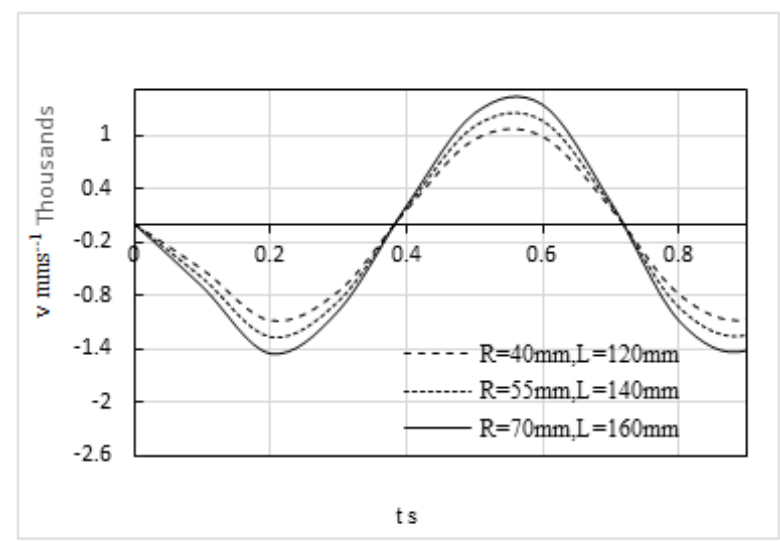

(d) $n=90 \mathrm{r} / \mathrm{m}$

Fig-4: Relations of strokes speed and time with the parameter $\mathbf{R} \& \mathbf{L}$ under different rotation

In Figure $4 \sim$ Figure 5 shows the curve of velocity and acceleration of two parameters. The condition in this paper is $R=40 \mathrm{~mm}, 55 \mathrm{~mm}$ and $70 \mathrm{~mm}$ and $\mathrm{L}=120 \mathrm{~mm}, 140 \mathrm{~mm}$ and $160 \mathrm{~mm}$. The similar status will be found too to compare with Figure 3. It is here not to mention again. The mentioning point is with increasing from $n=60 \mathrm{r} / \mathrm{m}, \mathrm{n}=70 \mathrm{r} / \mathrm{m}$ to $80 \mathrm{r} / \mathrm{m}$ the velocity will become big. That means that the high power will be formed here. The rotation of $70 \mathrm{r} / \mathrm{m}$ is needed in heavy load such as the thick thickness steel strip and the deepest cavity in production manufacture.
If the rotation is big the velocity of mold becomes big as well. So increasing rotation is to incline mold force from $60 \mathrm{r} / \mathrm{m}, 70 \mathrm{r} / \mathrm{m}$ to $80 \mathrm{r} / \mathrm{m}$ even $90 \mathrm{r} / \mathrm{m}$, it is one way to regulate.

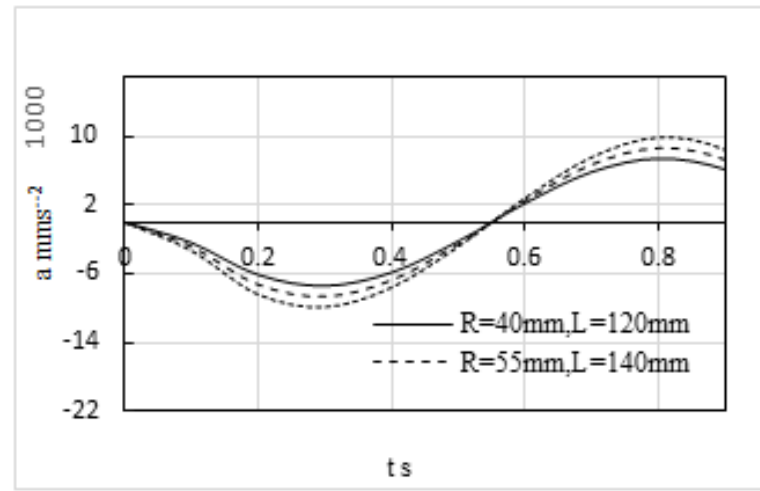

(a) $\mathrm{n}=60 \mathrm{r} / \mathrm{m}$

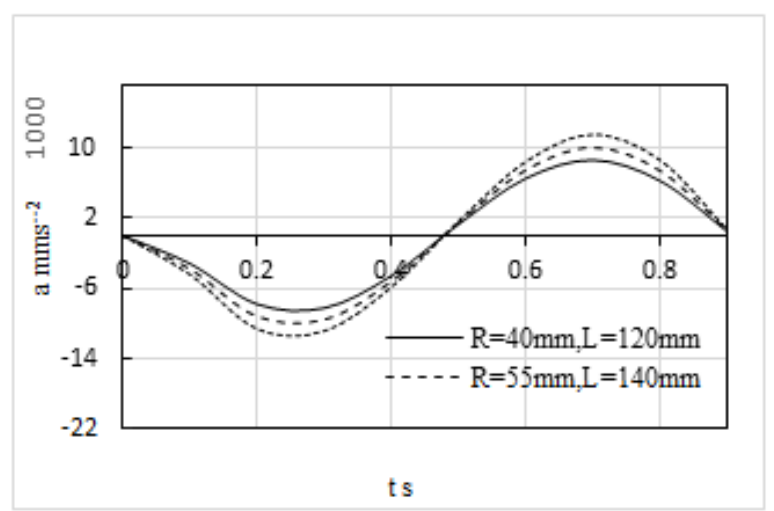

(a) $\mathrm{n}=70 \mathrm{r} / \mathrm{m}$

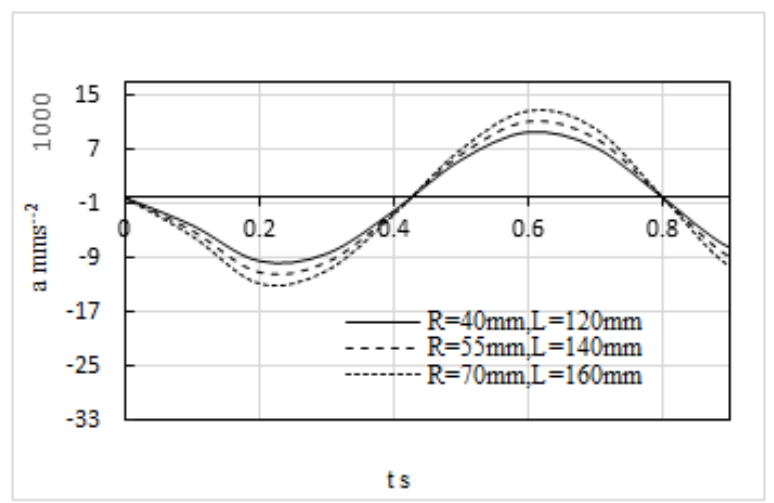

(a) $\mathrm{n}=80 \mathrm{r} / \mathrm{m}$

Fig-5: Relations of strokes acceleration and time with the parameter $R \& L$ under different rotation

Figure 5(a c) shows that the acceleration forms sinusoidal when the time increases and then it forms sinusoidal wave under $n=60 \mathrm{r} / \mathrm{m}, \mathrm{n}=70 \mathrm{r} / \mathrm{m}$ and $\mathrm{n}=80 \mathrm{r} / \mathrm{m}$. The summit was large when the time is 0.3 seconds, and then forms another summit with sinusoidal wave when the time is 0.8 seconds at $n=60 \mathrm{r} / \mathrm{m}$. Figure 5(b) curves summit change to be larger at $n=70 \mathrm{r} / \mathrm{m}$ while the phase angle becomes small. It indicates that the acceleration summit increases with increasing 
rotation, and repeats with rotation. Figure 5(c) shows that the acceleration of the mold will incline within the first $0.2 \mathrm{~s}$ which is smaller than rotation $\mathrm{n}=60 \mathrm{r} / \mathrm{m}$ and $\mathrm{n}=70 \mathrm{r} / \mathrm{m}$ when rotation inclines to $80 \mathrm{r} / \mathrm{m}$. It explains the movement is zero with center line so the biggest stamping happens. However the opposition movement stamping forms second summit which is smaller than the first one. With increasing linkage length the acceleration will incline. In general the power will become strong when long linkage length is. In the place where it needs small force the short linkage length is available for design.

\section{CONCLUSIONS}

1. The movement of mold becomes sinusoidal wave when the time changes. With the increase of time the mold speed becomes sinusoidal repeatedly. When the crank length and linkage length is big the movement and velocity shows big one. So to incline the force it is chosen of big stroke length and high rotation.

2. The similar status will happen in acceleration and the small acceleration summit forms then inclines at $0.6 \sim 0.8$ seconds subsequently in one cycle. So as time goes up the acceleration goes up and it goes to maximum in one cycle. When the rotation is big the acceleration inclines from $60 \mathrm{r} / \mathrm{m}$ to $90 \mathrm{r} / \mathrm{m}$.

\section{REFERENCES}

1. Run, X. U. (2020). Modeling of Economic Cost and Technological Control in Motor Housing Punch. Social Science Learning Education Journal, 5(09), 315-324.

2. Xu, R. (2020). The Kinematic Models of Crank with Angle and Time in Motor Housing Process.

3. Wu. W. (2019). Kinematics analysis of crank linkage length mechanism of internal combustion engine for vehicle, Internal Combustion Engine and Accessories, 5:72

4. Run, X. (2019). The Cost Control of mold Process [J], International Journal of Plant Engineering and Management, 24(3):187-192.

5. Li, J., Zhao, L., Liu, S., Ren, S. (2008). Dynamic simulation analysis of crank linkage length mechanism of type 4100 internal combustion engine, Equipment Manufacturing Technology, $12: 5$

6. Li, Chao-Bo., Lou, Jing-Jun. (2008). Dynamic analysis of crank railing mechanism of xingxing air compressor. Chinese Ship Research,5(13) : 98

7. Faculty of theoretical mechanics in Harbin Institute of Technology. (2011). Theoretical mechanics I[M], Higher Education Press, 267, 269, 272. 